\title{
Metagenomics-based evaluation of groundwater microbial profiles in response to treated wastewater discharge
}

\author{
Noor Zaouri ${ }^{1}$, Muhammad Raihan Jumat ${ }^{2}$, Tariq Cheema ${ }^{3}$ and Pei-Ying Hong ${ }^{1 *}$ \\ ${ }^{1}$ Water Desalination and Reuse Center (WDRC), Biological and Environmental Sciences and \\ Engineering Division (BESE), King Abdullah University of Science and Technology (KAUST), \\ Thuwal-Jeddah 23955-6900, Saudi Arabia \\ ${ }^{2}$ Duke-NUS Graduate Medical School, 8 College Road, Singapore 169857 \\ ${ }^{3}$ Hydrology Department, Faculty of Earth Sciences, King Abdulaziz University (KAU), Jeddah, \\ Saudi Arabia
}

* Corresponding author:

Pei-Ying Hong

Tel: +966-(12)-808-2218;

Email: peiying.hong@kaust.edu.sa 


\section{Highlights}

- Metagenomics as a tool to assess groundwater quality

- Lower alpha diversity of bacteria and virus due to treated wastewater exposure

- Increase in relative abundance of Planctomycetes and Picornaviridae

- Antibiotic resistance genes may not be good markers to differentiate wastewater exposure 
2

3

4

\section{Abstract}

3 This study aims to demonstrate the use of metagenomics to assess groundwater quality.

4 Metagenomics revealed a lower alpha diversity for both bacteria and virus in wastewater-

5 exposed groundwater compared to the upstream controls. However, an increase in the relative

6 abundance of Planctomycetes and Picornaviridae, as well as increasing counts of unique

7 antibiotic resistance genes, was observed in wastewater-exposed groundwater. Findings suggest

8 that metagenomics can detect microbial signatures indicative of treated wastewater discharge.

9

10

11

12

13 Keywords: Shotgun metagenomics; aquifer recharge; groundwater quality; water reuse 


\section{Introduction}

Water scarcity is projected to exacerbate by 2040, with 33 countries including Saudi Arabia predicted to face extreme water scarcity by that time (Luo et al., 2015). In recent years, recharging aquifer with treated wastewater has been proposed as a mitigation strategy to replenish the groundwater supplies. In Saudi Arabia, most wastewater treatment plants (WWTPs) are designed to achieve secondary or tertiary treatment with a final chlorination step prior to discharge. Such WWTPs typically achieve a cumulative 6-log reduction of microorganisms (Al-Jassim et al., 2015). Considering that untreated wastewater generally has a cell density of $10^{11}$ to $10^{12}$ cells/L (Manti et al., 2008), the final treated wastewater still contains a significant microbial load that may potentially perturb the indigenous groundwater microbial community. Aquifers are sensitive ecosystems, and therefore recharging aquifer with treated wastewater can only be adopted with an improved understanding on how these treated wastewater would affect the existing groundwater.

The current approaches to detecting changes in microbial community include qualitative approaches like terminal restriction fragment length polymorphism (T-RFLP) or quantitative approaches like real time PCR (qPCR). T-RFLP generates fingerprinting profiles for comparative analysis but does not provide information on the taxonomic identities of microbial contaminants. qPCR is a targeted approach that does not provide a comprehensive outlook on the wide variety of bacteria, virus and genes contaminants present in treated wastewater. The advent of high throughput untargeted sequencing approaches (e.g. metagenomics) have allowed a simultaneous evaluation on the bacteria, virus and genes present in an environmental sample (Quince et al., 2017). By comparing the diversity and relative abundance of these biological contaminants, one can denote if the groundwater has been perturbed by the treated wastewater. 
This study aims to demonstrate the use of metagenomics as a tool to assess microbial

39 water quality. Changes in the diversity and relative abundance of bacteria, virus and antibiotic

40 resistance genes were monitored to denote the extent of perturbation imposed by treated 41 wastewater.

\section{2. Material and method}

\section{$44 \quad$ 2.1. Description of sampling sites and sampling procedure}

45 A subsurface reservoir, otherwise also known as Wadi Fatimah in Arabic, situated along the 46 Yamaniyah-Az Zibarah-Fatimah drainage system in Saudi Arabia (Grainger, 1992) was 47 identified for groundwater monitoring. Wadi Fatimah has been receiving treated wastewaters as 48 part of a study commissioned in 2010-2016 by Makkah water utilities to recharge local aquifers. 49 Groundwater at this site was collected over a period of 9 months, and include the following: 50 wells 1, 15, 14 and 17 in March 2016; wells 1, 14 and 17 in August 2016; wells 12, 15 and 17 in 51 December 2016 (Figure S1). Treated wastewaters injected to Wadi Fatimah were from a local 52 WWTP upstream of well 1, and utilized schematics including clarifiers, activated sludge tanks, 53 oxidation ponds and chlorine disinfection. Sampling wells varied throughout the sampling period 54 because of various reasons including lack of sufficient water to facilitate representative 55 sampling, groundwater well was closed for access or no permission was granted from the well 56 owners on the day of sampling. Two wells situated approximately $60 \mathrm{~km}$ upstream of Wadi 57 Fatimah were also identified, and groundwater was collected from these wells during the same 58 time frame as mentioned above. Samples from these two wells serve as upstream controls since 59 both the wells are not known to actively receive any treated wastewater discharge (Figure S1). 60 The collected volume of all groundwater samples ranged from 20-40 L per well, and were 
61 comprised of a single grab sample collected per well per sampling event. Before collection, the

62 water was flushed for $>5$ min to remove stagnant pools of water retained within the sampling

63 pipes. Water was also flushed until no apparent turbidity was observed prior to collection in 64 sterile polyethylene bottles. All samples were placed into a cooler and kept cool during transport. 65 Upon arrival in laboratory, samples were stored in $4{ }^{\circ} \mathrm{C}$ prior to analyses.

\section{2.2. Groundwater concentration and DNA extraction}

67 Each 20-40 L of groundwater sample was passed through a filtration system fitted with a T68 series cassette with a 100-kDa cut-off (approximately $0.005 \mu \mathrm{m}$ ) (Pall Corporation, Port 69 Washington, NY, USA). This cassette has been shown previously to retain viruses at an 70 efficiency of up to $87 \%$ and was particularly suited for large volume concentration (Jumat et al., 71 2017). Hence, this procedure was chosen to concentrate any microbial matter present in the low 72 turbidity groundwater samples such as that collected in this study. Each groundwater sample was 73 concentrated to $5 \mathrm{~mL}$ of retentate. To collect any microbial matter adhering to the $100 \mathrm{kDa}$ 74 cassette, the system was washed with $50 \mathrm{~mL}$ of wash solution (1 x Phosphate Buffered Saline 75 (PBS) and $0.01 \%$ Tween 60). After circulating the wash solution through the filtration system for 76 several minutes, the wash solution was itself concentrated to $5 \mathrm{~mL}$. Both retentate and wash 77 solutions derived from the same sample were extracted for DNA was by using the DNeasy Blood 78 and Tissue Kit (Qiagen, Hilgen, Germany). MilliQ water was collected and subjected to the same 79 filtration procedure at the same time when all groundwater samples were filtered. This acts as a 80 negative control, and provide comparative analysis that would allow determination of microbial 81 populations unique to the groundwater.

\section{2.3. Metagenomic sequencing and analysis}


83 Genomic DNA was sent to CosmosID (Rockville, MD, USA) for sequencing on HiSeq, as 84 described (Hasan et al., 2014). Shotgun metagenomic datasets were directly analyzed by 85 CosmosID metagenomic software (CosmosID Inc., Rockville, MD) as described elsewhere 86 (Connelly et al., 2018; Hasan et al., 2014; Kaleko et al., 2016; Ponnusamy et al., 2016) to reveal 87 associated microbial community composition. Briefly, the system utilizes a high performance 88 data-mining k-mer algorithm and highly curated dynamic comparator databases (GenBook®) 89 that rapidly disambiguate millions of short reads into the discrete genomes or genes engendering 90 the particular sequences. The GeneBook databases were composed of over 150,000 microbial 91 genomes and gene sequences representing over 1000 bacterial and 5000 viral species, as well as 92 over 5500 antibiotic resistance genes. For each sample, the reads from a bacteria or viral species 93 are assigned to the strain with the highest aggregation statistics, and subsequently determined for 94 the corresponding alpha diversity. Community resistome was also identified using the CosmosID 95 Inc. bioinformatics software package by querying the unassembled sequence reads against the 96 CosmosID curated antibiotic resistance gene databases. Paired end Fastq files are deposited onto 97 European Nucleotide Archive under accession number PRJEB32173.

\section{2.4. Determination of organic water quality}

99 Organic constituents of the DOC were fractionated according to molecular weight (MW) with 100 size exclusion chromatography. The fraction distribution of the DOC in the groundwater was 101 analyzed using Liquid Chromatography equipped with a macro-porous silica separation column, 102 an Organic Carbon Detector (OCD), a UV $254 \mathrm{~nm}$ Detector (UVD) and an Organic Nitrogen 103 Detector (OND) (LC-OCD Model 8, DOC LABOR, Germany). ChromCaluni software was used 104 to determine the concentration of each fraction by integrating the area underneath the curve 105 according to manufacture instructions. 


\section{Results and discussion}

\subsection{Taxonomic profile of bacterial communities}

109 Phyla Proteobacteria, Actinobacteria and Bacteroidetes constitute the three dominant bacterial 110 groups in the groundwater samples of both Wadi Fatimah and upstream controls. However, 111 Proteobacteria and Actinobacteria were also present in high relative abundance in the negative 112 MilliQ controls (Figure 1a). In contrast, Bacteroidetes was detected in higher relative abundance 113 and in more consistent frequency in only the groundwater samples. Planctomycetes was detected 114 in higher relative abundance among the Wadi Fatimah samples than that in upstream and 115 negative controls (Figure 1a). Planctomycetes has been shown to be closely associated with 116 organic detritus in the marine environment (Halliday et al., 2014). Similarly, a higher relative 117 abundance of Planctomycetes was observed in groundwater samples that had a higher dissolved 118 organic carbon (Table 1). Among these five detected DOC fractions, building block (BB) and 119 humic substances (HS) were significantly higher in groundwater sampled from Wadi Fatimah 120 compared to upstream controls $(\mathrm{p}<0.10$, Table 1). Specifically, HS which is predominated by 121 aromatic moieties was only detected in Wadi Fatimah at concentrations ranging from 0.54 to $1220.70 \mathrm{mg} / \mathrm{L}$. Despite the higher DOC concentrations in Wadi Fatimah, the alpha diversity of 123 bacterial community was lower in all of its samples compared to the controls (Figure 1b), 124 suggesting the presence of an unknown factor that bias against certain families (e.g. 125 Bradyrhizobiaceae, Methylobacteriaceae) in Wadi Fatimah. These families were only detected in 126 the upstream controls during the sampling period. There was however, a positive trend of 127 increasing alpha diversity with time, although the reason behind this trend remains unknown.

\section{3.2. Community resistome}


Ninety six unique ARGs were detected in Wadi Fatimah while only 56 unique ARGs were detected in the upstream controls (Figure 1c). The 5 most abundant unique ARGs detected in Wadi Fatimah were related to aminoglycoside, beta-lactam, macrolide and quinolone resistance, while the 5 most abundant ARGs detected in upstream controls also included resistance against beta-lactam. Shared ARGs between Wadi Fatimah and control samples revealed additional genes conferring resistance to tetracycline and trimethoprim (Table 2). A positive detection of ARGs in both Wadi Fatimah and control samples suggests a ubiquitous presence of ARGs in most environments, including pristine environment (Van Goethem et al., 2018). This may be related to long term global consumption of antibiotics for both hospital-associated and communityacquired infections (Versporten et al., 2018). Hence, the choice of ARGs as metagenomics markers to denote anthropogenic contamination events may not be provide definitive results.

\subsection{Taxonomic profile of viral communities}

Podoviridae and Siphoviridae account as the two most dominant viral families in the groundwater (Figure 2a). It was further observed that upstream controls had a significantly higher relative abundance of Siphoviridae, along with Myoviridae, Inoviridae and Tectiviridae (p $<0.10)$. All four families are mainly comprised of bacteriophages that rely on bacteria and archaea as their natural hosts. Along with one of the negative controls which denoted an exceedingly high relative abundance of Picornaviridae, Picornaviridae was consistently detected in all groundwater samples and especially at a higher relative abundance in Wadi Fatimah samples (average 45\%) than in the upstream controls (average 11\%). Picornaviridae comprises of several notable human enteric viruses including Enteroviruses and Salivirus which are proposed as potential human virus indicator (Reuter et al., 2017). The high relative abundance of Picornaviridae may be related to the type of treatment process used by the WWTP situated in 

153 rates of viruses (Zhang and Farahbakhsh, 2007). In contrast, a WWTP retrofitted with membrane 154 bioreactor reported only sporadic occurrences of Enterovirus (Jumat et al., 2017). The alpha 155 diversity of viruses are higher in the controls than in Wadi Fatimah (Figure 2b). Coupled with 156 the higher abundance of families associated with bacteriophages, the higher alpha diversity may 157 be due to a wide variety of bacteriophages present in relatively unperturbed environments 158 compared to those exposed to treated wastewater. Unlike the bacterial alpha diversity, the viruses 159 did not exhibit an increasing trend of alpha diversity with time (Figure 2b).

\section{4. Conclusion}

162 Findings from this study demonstrates the use of metagenomics to provide a simultaneous

163 evaluation of bacteria, virus and antibiotic resistome in groundwater exposed to treated 164 wastewater discharge. It was observed that alpha diversity of both bacteria and viruses were 165 lower in exposed groundwater than the upstream controls. In addition, Planctomycetes and 166 Picornaviridae, both of which were detected by metagenomics simultaneously, may be 167 appropriate markers to indicate increased organic content and presence of human fecal 168 contamination. As more countries explore the use of treated wastewater to recharge diminishing 169 groundwater levels, metagenomics could suffice as an appropriate monitoring tool to ensure that 170 a wide diversity of biological contaminants are assessed and unintentional aberrations to the 171 groundwater minimized. However, metagenomics alone is unable to provide insights to the 172 potential risks that may arise from recharging aquifers with treated wastewater. This is because 173 metagenomics analysis does not provide absolute quantification of biological contaminants and 174 are derived from DNA template sequencing. Hence it is unable to differentiate the viable bacteria 
2

3

4

7

8

175 populations against the dead and non-infectious ones. Instead, metagenomics can possibly narrow down the suite of contaminants to a selected few (e.g. Picornaviridae) for more in-depth evaluation by other quantitative methods like quantitative PCR or digital PCR. By coupling metagenomics with other quantitative methods, potential risks arising from recharging aquifer 179 with treated wastewater can be better assessed.

\section{Acknowledgements}

183 The authors would like to thank Dr Moustapha Harb and Dhafer Alsaleh for assistance during 184 the early sampling years. The authors would also like to thank Professor Tom Missimer and Mr. 185 Mohammed AlRayaan for providing background information related to the hydrogeological 186 characteristics of Wadi Fatimah. This study is funded by KAUST Baseline Grant BAS/1/1033187 01-01 awarded to P.-Y. Hong. 


\begin{tabular}{|c|c|c|c|c|c|c|}
\hline & & \multicolumn{3}{|c|}{ Wadi Fatimah } & \multirow{2}{*}{$\begin{array}{c}\text { Upstream } \\
\text { controls }\end{array}$} & \multirow[t]{3}{*}{ P-value } \\
\hline & & March & August & December & & \\
\hline & & 2016 & 2016 & 2016 & & \\
\hline \multirow[t]{2}{*}{ DOC } & $\mathrm{mg} / \mathrm{L}$ & $8.59 \pm 3.23$ & $4.70 \pm 0.89$ & $6.12 \pm 4.43$ & $1.71 \pm 2.1$ & $0.08 *$ \\
\hline & & \multicolumn{3}{|c|}{ Carbon distribution } & & \\
\hline $\mathbf{B P}$ & $\mathrm{mg} / \mathrm{L}$ & $0.08 \pm 0.001$ & $0.04 \pm 0.01$ & $0.07 \pm 0.01$ & $0.02 \pm 0.05$ & 0.17 \\
\hline HS & $\mathrm{mg} / \mathrm{L}$ & $0.70 \pm 0.07$ & $0.62 \pm 0.02$ & $0.54 \pm 0.04$ & $0.04 \pm 0.05$ & $0.01 * *$ \\
\hline BB & $\mathrm{mg} / \mathrm{L}$ & $3.20 \pm 0.15$ & $2.58 \pm 0.34$ & $2.11 \pm 0.09$ & $0.68 \pm 0.88$ & $0.08 *$ \\
\hline $\begin{array}{c}\text { LMW } \\
\text { neutrals }\end{array}$ & $\mathrm{mg} / \mathrm{L}$ & $3.36 \pm 0.33$ & $0.58 \pm 0.06$ & $1.28 \pm 0.11$ & $0.14 \pm 0.06$ & 0.33 \\
\hline $\begin{array}{l}\text { LMW } \\
\text { acids }\end{array}$ & $\mathrm{mg} / \mathrm{L}$ & $1.13 \pm 0.107$ & $0.64 \pm 0.04$ & $1.56 \pm 0.23$ & $1.16 \pm 1.64$ & 0.95 \\
\hline
\end{tabular}

Table 1. Summary of the organic matter components in Wadi Fatimah and upstream controls. DOC denotes dissolved organic carbon, BP denotes biopolymers, HS denotes humic substances, BB denotes building blocks, LMW denotes low molecular weight. Statistical comparison was made using t-test between Wadi Fatimah samples and upstream controls. ** denotes significant difference at 95\% confidence level. * denotes significant difference at $90 \%$ confidence level. Value after \pm denotes standard deviation. 
Table 2. Antibiotic resistance genes detected in groundwater samples. ${ }^{*}$ denotes that the average percentage matched reads were already corrected for the average percentage detected in MilliQ control. N.D. denotes not detected or below detection limits.

\begin{tabular}{|c|c|c|c|}
\hline $\begin{array}{l}\text { Top } 5 \text { identified ARGs unique } \\
\text { to Wadi Fatimah }\end{array}$ & $\begin{array}{l}\text { Average \% total } \\
\text { matches * }\end{array}$ & $\begin{array}{l}\text { Average } \\
\% \text { in } \\
\text { MilliQ } \\
\text { control }\end{array}$ & Denoted function \\
\hline Aminoglycoside $a p h 3^{\prime} I a$ & 0.03 & N.D. & $\begin{array}{l}\text { Aminoglycoside phosphotransferase gene, confers resistance by } \\
\text { catalyzing the addition of phosphate from ATP to the 3'-hydroxyl group } \\
\text { of a 4,6-disubstituted aminoglycoside }\end{array}$ \\
\hline Aminoglycoside a adAl3 & 0.04 & N.D. & $\begin{array}{l}\text { Aminoglycoside nucleotidyltransferase gene, confers resistance by } \\
\text { adenylating the 2"-hydroxyl group of aminoglycoside }\end{array}$ \\
\hline Beta-lactam-resistance $b l a_{C A U-1}$ & 0.04 & N.D. & $\begin{array}{l}\text { Metallo- } \beta \text {-lactamase gene, confers resistance by catalyzing the } \\
\text { hydrolysis of beta-lactam }\end{array}$ \\
\hline Macrolide ereA & 0.05 & 0.01 & $\begin{array}{l}\text { Erythromycin esterase gene, confers resistance through inactivation by } \\
\text { hydrolyzing the lactone ring of the antibiotic }\end{array}$ \\
\hline $\begin{array}{l}\text { Plasmid-mediated-quinolone- } \\
\text { resistance } q n r D 1\end{array}$ & 0.04 & & $\begin{array}{l}\text { Quinolone resistance gene, confers resistance by preventing antibiotic } \\
\text { binding }\end{array}$ \\
\hline $\begin{array}{l}\text { Top } 5 \text { identified ARGs unique } \\
\text { to upstream controls }\end{array}$ & $\begin{array}{l}\text { Average \% total } \\
\text { matches * }\end{array}$ & $\begin{array}{l}\text { Average } \\
\% \text { in } \\
\text { MilliQ } \\
\text { control }\end{array}$ & Denoted function \\
\hline Multidrug efflux pump $m d t E$ & 0.14 & 0.15 & $\begin{array}{l}\text { Part of the tripartite efflux system MdtEF-TolC, which confers } \\
\text { resistance to compounds such as erythromycin, doxorubicin, } \\
\text { benzalkonium and so on }\end{array}$ \\
\hline $\begin{array}{l}\text { Repressor for multidrug efflux } \\
\text { pump emrR }\end{array}$ & 0.12 & 0.13 & $\begin{array}{l}\text { Negatively regulates the transcription of the multidrug resistance pump- } \\
\text { encoding operon, emrRAB, by binding to its regulatory region }\end{array}$ \\
\hline Sensor kinase $c p x A$ & 0.11 & 0.13 & $\begin{array}{l}\text { Histidine kinase member of the two-component regulatory } \\
\text { system } \mathrm{CpxA} / \mathrm{CpxR} \text {, responds to envelope stress response }\end{array}$ \\
\hline Beta-lactam-resistance $b l a_{O X A} 281$ & 0.10 & N.D. & $\begin{array}{l}\text { Oxacillinase (enzyme that confers resistance to oxacillin, a type of beta- } \\
\text { lactam), presumably intrinsic to Acinetobacter johnsonii SH046 }\end{array}$ \\
\hline Beta-lactam-resistance $b l a_{O X A} 211$ & 0.09 & N.D. & $\begin{array}{l}\text { Oxacillinase (enzyme that confers resistance to oxacillin, a type of beta- } \\
\text { lactam), presumably intrinsic to Acinetobacter johnsonii SH046 }\end{array}$ \\
\hline
\end{tabular}




\begin{tabular}{|l|l|l|l|l|}
\hline $\begin{array}{l}\text { ARGs identified in Wadi } \\
\text { Fatimah and upstream } \\
\text { controls }\end{array}$ & $\begin{array}{l}\text { Average } \\
\% \text { total } \\
\text { matches } \\
\text { in Wadi } \\
\text { Fatimah* }\end{array}$ & $\begin{array}{l}\text { Average \% } \\
\text { total } \\
\text { matches in } \\
\text { upstream } \\
\text { control* }\end{array}$ & $\begin{array}{l}\text { Average } \\
\text { \% in } \\
\text { MilliQ } \\
\text { control }\end{array}$ & Denoted function \\
\hline Beta-lactam-resistance $b l a_{O X A-212}$ & 0.04 & 0.10 & N.D. & $\begin{array}{l}\text { Carbapenem-hydrolyzing class D beta-lactamase, confers resistance by } \\
\text { catalyzing the hydrolysis of beta-lactam }\end{array}$ \\
\hline Beta-lactam-resistance $b l a_{O X A-373}$ & 0.03 & 0.14 & $\begin{array}{l}\text { Functions as a transpeptidase, beta-lactam became suicide substrates } \\
\text { of transpeptidases }\end{array}$ \\
\hline Tetracycline $t e t 39$ & 0.04 & 0.16 & $\begin{array}{l}\text { Tetracycline resistance gene, confers resistance by active efflux } \\
\text { mechanisms }\end{array}$ \\
\hline Tetracycline $t e t R G$ & 0.05 & 0.09 & $\begin{array}{l}\text { TetR is the repressor of the tetracycline resistance element, TetG is } \\
\text { tetracycline efflux protein }\end{array}$ \\
\hline Trimethoprim $d f r 32$ & 0.05 & 0.03 & $\begin{array}{l}\text { Dihydrofolate reductase and trimethoprim resistance gene, confers } \\
\text { resistance by replacing or substituting antibiotic action target }\end{array}$ \\
\hline
\end{tabular}




\section{Figure legends}

201 Figure 1. Bacterial communities and bacteria-associated antibiotic resistome in groundwater. (a) 202 Heat map illustrates relative abundance of individual bacteria phyla in the negative controls 203 (MilliQ water), upstream controls and wells in Wadi Fatimah across different sampling months.

204 (b) Bacteria alpha diversity in groundwater sampled from Wadi Fatimah across different 205 sampling months, upstream controls and negative controls. Linear line depicts an increasing 206 trend in alpha diversity with time. (c) Venn diagram illustrating the number of unique antibiotic 207 resistance genes detected in Wadi Fatimah (depicted as green) and upstream control samples 208 (depicted as red). Overlapping region shows the number of shared antibiotic resistance genes 209 detected in both Wadi Fatimah and upstream controls.

210 Figure 2. Viral communities in groundwater. (a) Heat map illustrates the relative abundance of 211 individual viral families in the control (MilliQ water), upstream controls and wells in Wadi 212 Fatimah across the different sampling times. (b) Virus alpha diversity in groundwater sampled 213 from Wadi Fatimah across different sampling months, upstream controls and negative controls. 214 Linear line depicts no apparent trend of increment with time. .

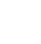

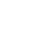

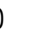
. 3 


\section{References}

Al-Jassim, N., et al., 2015. Removal of bacterial contaminants and antibiotic resistance genes by conventional wastewater treatment processes in Saudi Arabia: Is the treated wastewater safe to reuse for agricultural irrigation? Water Res. 73, 277-90.

Connelly, S., et al., 2018. Distinct consequences of amoxicillin and ertapenem exposure in the porcine gut microbiome. Anaerobe. 53, 82-93.

Grainger, D. J., 1992. A geological excursion in the Wadi Fatima area, near Jiddah, Saudi Arabia. Geology Today. 8, 215-219.

Halliday, E., et al., 2014. Comparison of bacterial communities in sands and water at beaches with bacterial water quality violations. PLoS One. 9, e90815.

Hasan, N. A., et al., 2014. Microbial Community Profiling of Human Saliva Using Shotgun Metagenomic Sequencing. Plos One. 9.

Jumat, M. R., et al., 2017. Membrane Bioreactor-Based Wastewater Treatment Plant in Saudi Arabia: Reduction of Viral Diversity, Load, and Infectious Capacity. Water. 9.

Kaleko, M., et al., 2016. Development of SYN-004, an oral beta-lactamase treatment to protect the gut microbiome from antibiotic-mediated damage and prevent Clostridium difficile infection. Anaerobe. 41, 58-67.

Luo, T., et al., Aqueduct Projected Water Stress Country Rankings. 2015. http://reliefweb.int/sites/reliefweb.int/files/resources/AQUEDUCT\%20PROJECTED\%20WATER\% 20STRESS\%20Country\%20Rankings.pdf. 31 August 2019

Manti, A., et al., 2008. Bacterial cell monitoring in wastewater treatment plants by flow cytometry. Water Environ Res. 80, 346-54.

Ponnusamy, D., et al., 2016. Cross-talk among flesh-eating Aeromonas hydrophila strains in mixed infection leading to necrotizing fasciitis. Proceedings of the National Academy of Sciences. 113, 722-727.

Quince, C., et al., 2017. Shotgun metagenomics, from sampling to analysis. Nature Biotechnology. 35, 833.

Reuter, G., et al., 2017. Saliviruses-the first knowledge about a newly discovered human picornavirus. Rev Med Virol. 27.

Van Goethem, M. W., et al., 2018. A reservoir of 'historical' antibiotic resistance genes in remote pristine Antarctic soils. Microbiome. 6, 40.

Versporten, A., et al., 2018. Antimicrobial consumption and resistance in adult hospital inpatients in 53 countries: results of an internet-based global point prevalence survey. Lancet Glob Health. 6, e619-e629.

Zhang, K., Farahbakhsh, K., 2007. Removal of native coliphages and coliform bacteria from municipal wastewater by various wastewater treatment processes: implications to water reuse. Water Res. 41, 2816-24. 


\title{
Metagenomics-based evaluation of groundwater microbial profiles in response to treated wastewater discharge
}

\author{
Noor Zaouri ${ }^{1}$, Muhammad Raihan Jumat ${ }^{2}$, Tariq Cheema ${ }^{3}$ and Pei-Ying Hong ${ }^{1 *}$ \\ ${ }^{1}$ Water Desalination and Reuse Center (WDRC), Biological and Environmental Sciences and \\ Engineering Division (BESE), King Abdullah University of Science and Technology (KAUST), \\ Thuwal-Jeddah 23955-6900, Saudi Arabia \\ ${ }^{2}$ Duke-NUS Graduate Medical School, 8 College Road, Singapore 169857 \\ ${ }^{3}$ Hydrology Department, Faculty of Earth Sciences, King Abdulaziz University (KAU), Jeddah, \\ Saudi Arabia
}

* Corresponding author:

Pei-Ying Hong

Tel: +966-(12)-808-2218;

Email: peiying.hong@kaust.edu.sa 


\section{Highlights}

- Metagenomics as a tool to assess groundwater quality

- Lower alpha diversity of bacteria and virus due to treated wastewater exposure

- Increase in relative abundance of Planctomycetes and Picornaviridae

- Antibiotic resistance genes may not be good markers to differentiate wastewater exposure 
2

3

4

\section{Abstract}

3 This study aims to demonstrate the use of metagenomics to assess groundwater quality.

4 Metagenomics revealed a lower alpha diversity for both bacteria and virus in wastewater-

5 exposed groundwater compared to the upstream controls. However, an increase in the relative

6 abundance of Planctomycetes and Picornaviridae, as well as increasing counts of unique

7 antibiotic resistance genes, was observed in wastewater-exposed groundwater. Findings suggest

8 that metagenomics can detect microbial signatures indicative of treated wastewater discharge.

9

10

11

12

13 Keywords: Shotgun metagenomics; aquifer recharge; groundwater quality; water reuse 


\section{Introduction}

Water scarcity is projected to exacerbate by 2040, with 33 countries including Saudi Arabia predicted to face extreme water scarcity by that time (Luo et al., 2015). In recent years, recharging aquifer with treated wastewater has been proposed as a mitigation strategy to replenish the groundwater supplies. In Saudi Arabia, most wastewater treatment plants (WWTPs) are designed to achieve secondary or tertiary treatment with a final chlorination step prior to discharge. Such WWTPs typically achieve a cumulative 6-log reduction of microorganisms (Al-Jassim et al., 2015). Considering that untreated wastewater generally has a cell density of $10^{11}$ to $10^{12}$ cells/L (Manti et al., 2008), the final treated wastewater still contains a significant microbial load that may potentially perturb the indigenous groundwater microbial community. Aquifers are sensitive ecosystems, and therefore recharging aquifer with treated wastewater can only be adopted with an improved understanding on how these treated wastewater would affect the existing groundwater.

The current approaches to detecting changes in microbial community include qualitative approaches like terminal restriction fragment length polymorphism (T-RFLP) or quantitative approaches like real time PCR (qPCR). T-RFLP generates fingerprinting profiles for comparative analysis but does not provide information on the taxonomic identities of microbial contaminants. qPCR is a targeted approach that does not provide a comprehensive outlook on the wide variety of bacteria, virus and genes contaminants present in treated wastewater. The advent of high throughput untargeted sequencing approaches (e.g. metagenomics) have allowed a simultaneous evaluation on the bacteria, virus and genes present in an environmental sample (Quince et al., 2017). By comparing the diversity and relative abundance of these biological contaminants, one can denote if the groundwater has been perturbed by the treated wastewater. 
This study aims to demonstrate the use of metagenomics as a tool to assess microbial

39 water quality. Changes in the diversity and relative abundance of bacteria, virus and antibiotic

40 resistance genes were monitored to denote the extent of perturbation imposed by treated 41 wastewater.

\section{2. Material and method}

\section{$44 \quad$ 2.1. Description of sampling sites and sampling procedure}

45 A subsurface reservoir, otherwise also known as Wadi Fatimah in Arabic, situated along the 46 Yamaniyah-Az Zibarah-Fatimah drainage system in Saudi Arabia (Grainger, 1992) was 47 identified for groundwater monitoring. Wadi Fatimah has been receiving treated wastewaters as 48 part of a study commissioned in 2010-2016 by Makkah water utilities to recharge local aquifers. 49 Groundwater at this site was collected over a period of 9 months, and include the following: 50 wells 1, 15, 14 and 17 in March 2016; wells 1, 14 and 17 in August 2016; wells 12, 15 and 17 in 51 December 2016 (Figure S1). Treated wastewaters injected to Wadi Fatimah were from a local 52 WWTP upstream of well 1, and utilized schematics including clarifiers, activated sludge tanks, 53 oxidation ponds and chlorine disinfection. Sampling wells varied throughout the sampling period 54 because of various reasons including lack of sufficient water to facilitate representative 55 sampling, groundwater well was closed for access or no permission was granted from the well 56 owners on the day of sampling. Two wells situated approximately $60 \mathrm{~km}$ upstream of Wadi 57 Fatimah were also identified, and groundwater was collected from these wells during the same 58 time frame as mentioned above. Samples from these two wells serve as upstream controls since 59 both the wells are not known to actively receive any treated wastewater discharge (Figure S1). 60 The collected volume of all groundwater samples ranged from 20-40 L per well, and were 
61 comprised of a single grab sample collected per well per sampling event. Before collection, the

62 water was flushed for $>5$ min to remove stagnant pools of water retained within the sampling

63 pipes. Water was also flushed until no apparent turbidity was observed prior to collection in 64 sterile polyethylene bottles. All samples were placed into a cooler and kept cool during transport. 65 Upon arrival in laboratory, samples were stored in $4{ }^{\circ} \mathrm{C}$ prior to analyses.

\section{2.2. Groundwater concentration and DNA extraction}

67 Each 20-40 L of groundwater sample was passed through a filtration system fitted with a T68 series cassette with a 100-kDa cut-off (approximately $0.005 \mu \mathrm{m}$ ) (Pall Corporation, Port 69 Washington, NY, USA). This cassette has been shown previously to retain viruses at an 70 efficiency of up to $87 \%$ and was particularly suited for large volume concentration (Jumat et al., 71 2017). Hence, this procedure was chosen to concentrate any microbial matter present in the low 72 turbidity groundwater samples such as that collected in this study. Each groundwater sample was 73 concentrated to $5 \mathrm{~mL}$ of retentate. To collect any microbial matter adhering to the $100 \mathrm{kDa}$ 74 cassette, the system was washed with $50 \mathrm{~mL}$ of wash solution (1 x Phosphate Buffered Saline 75 (PBS) and $0.01 \%$ Tween 60). After circulating the wash solution through the filtration system for 76 several minutes, the wash solution was itself concentrated to $5 \mathrm{~mL}$. Both retentate and wash 77 solutions derived from the same sample were extracted for DNA was by using the DNeasy Blood 78 and Tissue Kit (Qiagen, Hilgen, Germany). MilliQ water was collected and subjected to the same 79 filtration procedure at the same time when all groundwater samples were filtered. This acts as a 80 negative control, and provide comparative analysis that would allow determination of microbial 81 populations unique to the groundwater. 


\subsection{Metagenomic sequencing and analysis}

85 Genomic DNA was sent to CosmosID (Rockville, MD, USA) for sequencing on HiSeq, as

86 described (Hasan et al., 2014). Shotgun metagenomic datasets were directly analyzed by 87 CosmosID metagenomic software (CosmosID Inc., Rockville, MD) as described elsewhere 88 (Connelly et al., 2018; Hasan et al., 2014; Kaleko et al., 2016; Ponnusamy et al., 2016) to reveal 89 associated microbial community composition. Briefly, the system utilizes a high performance 90 data-mining k-mer algorithm and highly curated dynamic comparator databases (GenBook®) 91 that rapidly disambiguate millions of short reads into the discrete genomes or genes engendering 92 the particular sequences. The GeneBook databases were composed of over 150,000 microbial 93 genomes and gene sequences representing over 1000 bacterial and 5000 viral species, as well as 94 over 5500 antibiotic resistance genes. For each sample, the reads from a bacteria or viral species 95 are assigned to the strain with the highest aggregation statistics, and subsequently determined for 96 the corresponding alpha diversity. Community resistome was also identified using the CosmosID 97 Inc. bioinformatics software package by querying the unassembled sequence reads against the 98 CosmosID curated antibiotic resistance gene databases. Paired end Fastq files are deposited onto 99 European Nucleotide Archive under accession number PRJEB32173.

\section{2.4. Determination of organic water quality}

101 Organic constituents of the DOC were fractionated according to molecular weight (MW) with 102 size exclusion chromatography. The fraction distribution of the DOC in the groundwater was 103 analyzed using Liquid Chromatography equipped with a macro-porous silica separation column, 104 an Organic Carbon Detector (OCD), a UV $254 \mathrm{~nm}$ Detector (UVD) and an Organic Nitrogen 
105 Detector (OND) (LC-OCD Model 8, DOC LABOR, Germany). ChromCaluni software was used

106 to determine the concentration of each fraction by integrating the area underneath the curve

107 according to manufacture instructions.

108 3. Results and discussion

109 3.1. Taxonomic profile of bacterial communities

111 Phyla Proteobacteria, Actinobacteria and Bacteroidetes constitute the three dominant bacterial 112 groups in the groundwater samples of both Wadi Fatimah and upstream controls. However, 113 Proteobacteria and Actinobacteria were also present in high relative abundance in the negative 114 MilliQ controls (Figure 1a). In contrast, Bacteroidetes was detected in higher relative abundance 115 and in more consistent frequency in only the groundwater samples. Planctomycetes was detected 116 in higher relative abundance among the Wadi Fatimah samples than that in upstream and 117 negative controls (Figure 1a). Planctomycetes has been shown to be closely associated with 118 organic detritus in the marine environment (Halliday et al., 2014). Similarly, a higher relative 119 abundance of Planctomycetes was observed in groundwater samples that had a higher dissolved 120 organic carbon (Table 1). Among these five detected DOC fractions, building block (BB) and 121 humic substances (HS) were significantly higher in groundwater sampled from Wadi Fatimah 122 compared to upstream controls ( $\mathrm{p}<0.10$, Table 1). Specifically, HS which is predominated by 123 aromatic moieties was only detected in Wadi Fatimah at concentrations ranging from 0.54 to $1240.70 \mathrm{mg} / \mathrm{L}$. Despite the higher DOC concentrations in Wadi Fatimah, the alpha diversity of 125 bacterial community was lower in all of its samples compared to the controls (Figure 1b), 126 suggesting the presence of an unknown factor that bias against certain families (e.g. 127 Bradyrhizobiaceae, Methylobacteriaceae) in Wadi Fatimah. These families were only detected in 
128 the upstream controls during the sampling period. There was however, a positive trend of 129 increasing alpha diversity with time, although the reason behind this trend remains unknown.

\subsection{Community resistome}

Ninety six unique ARGs were detected in Wadi Fatimah while only 56 unique ARGs were detected in the upstream controls (Figure 1c). The 5 most abundant unique ARGs detected in Wadi Fatimah were related to aminoglycoside, beta-lactam, macrolide and quinolone resistance, while the 5 most abundant ARGs detected in upstream controls also included resistance against beta-lactam. Shared ARGs between Wadi Fatimah and control samples revealed additional genes conferring resistance to tetracycline and trimethoprim (Table 2). A positive detection of ARGs in both Wadi Fatimah and control samples suggests a ubiquitous presence of ARGs in most environments, including pristine environment (Van Goethem et al., 2018). This may be related to long term global consumption of antibiotics for both hospital-associated and communityacquired infections (Versporten et al., 2018). Hence, the choice of ARGs as metagenomics markers to denote anthropogenic contamination events may not be provide definitive results.

\subsection{Taxonomic profile of viral communities}

Podoviridae and Siphoviridae account as the two most dominant viral families in the groundwater (Figure 2a). It was further observed that upstream controls had a significantly higher relative abundance of Siphoviridae, along with Myoviridae, Inoviridae and Tectiviridae (p $<0.10)$. All four families are mainly comprised of bacteriophages that rely on bacteria and archaea as their natural hosts. Along with one of the negative controls which denoted an exceedingly high relative abundance of Picornaviridae, Picornaviridae was consistently detected in all groundwater samples and especially at a higher relative abundance in Wadi Fatimah 
151 of several notable human enteric viruses including Enteroviruses and Salivirus which are 152 proposed as potential human virus indicator (Reuter et al., 2017). The high relative abundance of 153 Picornaviridae may be related to the type of treatment process used by the WWTP situated in 154 Wadi Fatimah. Secondary and tertiary treatment processes typically do not achieve high removal 155 rates of viruses (Zhang and Farahbakhsh, 2007). In contrast, a WWTP retrofitted with membrane 156 bioreactor reported only sporadic occurrences of Enterovirus (Jumat et al., 2017). The alpha 157 diversity of viruses are higher in the controls than in Wadi Fatimah (Figure 2b). Coupled with 158 the higher abundance of families associated with bacteriophages, the higher alpha diversity may 159 be due to a wide variety of bacteriophages present in relatively unperturbed environments 160 compared to those exposed to treated wastewater. Unlike the bacterial alpha diversity, the viruses 161 did not exhibit an increasing trend of alpha diversity with time (Figure 2b). 163 164 165 166

\section{Conclusion}

Findings from this study demonstrates the use of metagenomics to provide a simultaneous evaluation of bacteria, virus and antibiotic resistome in groundwater exposed to treated wastewater discharge. It was observed that alpha diversity of both bacteria and viruses were lower in exposed groundwater than the upstream controls. In addition, Planctomycetes and Picornaviridae, both of which were detected by metagenomics simultaneously, may be appropriate markers to indicate increased organic content and presence of human fecal contamination. As more countries explore the use of treated wastewater to recharge diminishing groundwater levels, metagenomics could suffice as an appropriate monitoring tool to ensure that a wide diversity of biological contaminants are assessed and unintentional aberrations to the 
173 groundwater minimized. However, metagenomics alone is unable to provide insights to the 174 potential risks that may arise from recharging aquifers with treated wastewater. This is because 175 metagenomics analysis does not provide absolute quantification of biological contaminants and 176 are derived from DNA template sequencing. Hence it is unable to differentiate the viable bacteria 177 populations against the dead and non-infectious ones. Instead, metagenomics can possibly 178 narrow down the suite of contaminants to a selected few (e.g. Picornaviridae) for more in-depth 179 evaluation by other quantitative methods like quantitative PCR or digital PCR. By coupling 180 metagenomics with other quantitative methods, potential risks arising from recharging aquifer 181 with treated wastewater can be better assessed.

\section{Acknowledgements}

185 The authors would like to thank Dr Moustapha Harb and Dhafer Alsaleh for assistance during 186 the early sampling years. The authors would also like to thank Professor Tom Missimer and Mr.

187 Mohammed AlRayaan for providing background information related to the hydrogeological 188 characteristics of Wadi Fatimah. This study is funded by KAUST Baseline Grant BAS/1/1033189 01-01 awarded to P.-Y. Hong. 


\begin{tabular}{|c|c|c|c|c|c|c|}
\hline & & \multicolumn{3}{|c|}{ Wadi Fatimah } & \multirow{2}{*}{$\begin{array}{c}\text { Upstream } \\
\text { controls }\end{array}$} & \multirow[t]{3}{*}{ P-value } \\
\hline & & March & August & December & & \\
\hline & & 2016 & 2016 & 2016 & & \\
\hline \multirow[t]{2}{*}{ DOC } & $\mathrm{mg} / \mathrm{L}$ & $8.59 \pm 3.23$ & $4.70 \pm 0.89$ & $6.12 \pm 4.43$ & $1.71 \pm 2.1$ & $0.08 *$ \\
\hline & & \multicolumn{3}{|c|}{ Carbon distribution } & & \\
\hline $\mathbf{B P}$ & $\mathrm{mg} / \mathrm{L}$ & $0.08 \pm 0.001$ & $0.04 \pm 0.01$ & $0.07 \pm 0.01$ & $0.02 \pm 0.05$ & 0.17 \\
\hline HS & $\mathrm{mg} / \mathrm{L}$ & $0.70 \pm 0.07$ & $0.62 \pm 0.02$ & $0.54 \pm 0.04$ & $0.04 \pm 0.05$ & $0.01 * *$ \\
\hline BB & $\mathrm{mg} / \mathrm{L}$ & $3.20 \pm 0.15$ & $2.58 \pm 0.34$ & $2.11 \pm 0.09$ & $0.68 \pm 0.88$ & $0.08 *$ \\
\hline $\begin{array}{c}\text { LMW } \\
\text { neutrals }\end{array}$ & $\mathrm{mg} / \mathrm{L}$ & $3.36 \pm 0.33$ & $0.58 \pm 0.06$ & $1.28 \pm 0.11$ & $0.14 \pm 0.06$ & 0.33 \\
\hline $\begin{array}{l}\text { LMW } \\
\text { acids }\end{array}$ & $\mathrm{mg} / \mathrm{L}$ & $1.13 \pm 0.107$ & $0.64 \pm 0.04$ & $1.56 \pm 0.23$ & $1.16 \pm 1.64$ & 0.95 \\
\hline
\end{tabular}

Table 1. Summary of the organic matter components in Wadi Fatimah and upstream controls. DOC denotes dissolved organic carbon, BP denotes biopolymers, HS denotes humic substances, BB denotes building blocks, LMW denotes low molecular weight. Statistical comparison was made using t-test between Wadi Fatimah samples and upstream controls. ** denotes significant difference at 95\% confidence level. * denotes significant difference at $90 \%$ confidence level. Value after \pm denotes standard deviation. 
Table 2. Antibiotic resistance genes detected in groundwater samples. * denotes that the average percentage matched reads were already corrected for the average percentage detected in MilliQ control. N.D. denotes not detected or below detection limits.

\begin{tabular}{|c|c|c|c|}
\hline $\begin{array}{l}\text { Top } 5 \text { identified ARGs unique } \\
\text { to Wadi Fatimah }\end{array}$ & $\begin{array}{l}\text { Average \% total } \\
\text { matches } *\end{array}$ & $\begin{array}{l}\text { Average } \\
\% \text { in } \\
\text { MilliQ } \\
\text { control }\end{array}$ & Denoted function \\
\hline Aminoglycoside $a p h 3^{\prime} I a$ & 0.03 & N.D. & $\begin{array}{l}\text { Aminoglycoside phosphotransferase gene, confers resistance by } \\
\text { catalyzing the addition of phosphate from ATP to the 3'-hydroxyl group } \\
\text { of a 4,6-disubstituted aminoglycoside }\end{array}$ \\
\hline Aminoglycoside a adA 13 & 0.04 & N.D. & $\begin{array}{l}\text { Aminoglycoside nucleotidyltransferase gene, confers resistance by } \\
\text { adenylating the 2"-hydroxyl group of aminoglycoside }\end{array}$ \\
\hline Beta-lactam-resistance $b l a_{C A U-1}$ & 0.04 & N.D. & $\begin{array}{l}\text { Metallo- } \beta \text {-lactamase gene, confers resistance by catalyzing the } \\
\text { hydrolysis of beta-lactam }\end{array}$ \\
\hline Macrolide ereA & 0.05 & 0.01 & $\begin{array}{l}\text { Erythromycin esterase gene, confers resistance through inactivation by } \\
\text { hydrolyzing the lactone ring of the antibiotic }\end{array}$ \\
\hline $\begin{array}{l}\text { Plasmid-mediated-quinolone- } \\
\text { resistance } q n r D 1\end{array}$ & 0.04 & & $\begin{array}{l}\text { Quinolone resistance gene, confers resistance by preventing antibiotic } \\
\text { binding }\end{array}$ \\
\hline $\begin{array}{l}\text { Top } 5 \text { identified ARGs unique } \\
\text { to upstream controls }\end{array}$ & $\begin{array}{l}\text { Average \% total } \\
\text { matches } *\end{array}$ & $\begin{array}{l}\text { Average } \\
\% \text { in } \\
\text { MilliQ } \\
\text { control }\end{array}$ & Denoted function \\
\hline Multidrug efflux pump $m d t E$ & 0.14 & 0.15 & $\begin{array}{l}\text { Part of the tripartite efflux system MdtEF-TolC, which confers } \\
\text { resistance to compounds such as erythromycin, doxorubicin, } \\
\text { benzalkonium and so on }\end{array}$ \\
\hline $\begin{array}{l}\text { Repressor for multidrug efflux } \\
\text { pump emrR }\end{array}$ & 0.12 & 0.13 & $\begin{array}{l}\text { Negatively regulates the transcription of the multidrug resistance pump- } \\
\text { encoding operon, emrRAB, by binding to its regulatory region }\end{array}$ \\
\hline Sensor kinase $c p x A$ & 0.11 & 0.13 & $\begin{array}{l}\text { Histidine kinase member of the two-component regulatory } \\
\text { system CpxA/CpxR, responds to envelope stress response }\end{array}$ \\
\hline Beta-lactam-resistance $b l a_{O X A} 281$ & 0.10 & N.D. & $\begin{array}{l}\text { Oxacillinase (enzyme that confers resistance to oxacillin, a type of beta- } \\
\text { lactam), presumably intrinsic to Acinetobacter johnsonii SH046 }\end{array}$ \\
\hline Beta-lactam-resistance $b l a_{O X A} 211$ & 0.09 & N.D. & $\begin{array}{l}\text { Oxacillinase (enzyme that confers resistance to oxacillin, a type of beta- } \\
\text { lactam), presumably intrinsic to Acinetobacter johnsonii SH046 }\end{array}$ \\
\hline
\end{tabular}




\begin{tabular}{|l|l|l|l|l|}
\hline $\begin{array}{l}\text { ARGs identified in Wadi } \\
\text { Fatimah and upstream } \\
\text { controls }\end{array}$ & $\begin{array}{l}\text { Average } \\
\% \text { total } \\
\text { matches } \\
\text { in Wadi } \\
\text { Fatimah* }\end{array}$ & $\begin{array}{l}\text { Average \% } \\
\text { total } \\
\text { matches in } \\
\text { upstream } \\
\text { control* }\end{array}$ & $\begin{array}{l}\text { Average } \\
\% \text { in } \\
\text { MilliQ } \\
\text { control }\end{array}$ & Denoted function \\
\hline Beta-lactam-resistance $b l a_{O X A-212}$ & 0.04 & 0.10 & N.D. & $\begin{array}{l}\text { Carbapenem-hydrolyzing class D beta-lactamase, confers resistance by } \\
\text { catalyzing the hydrolysis of beta-lactam }\end{array}$ \\
\hline Beta-lactam-resistance $b l a_{O X A-373}$ & 0.03 & 0.14 & $\begin{array}{l}\text { Functions as a transpeptidase, beta-lactam became suicide substrates } \\
\text { of transpeptidases }\end{array}$ \\
\hline Tetracycline $t e t 39$ & 0.04 & 0.16 & $\begin{array}{l}\text { Tetracycline resistance gene, confers resistance by active efflux } \\
\text { mechanisms }\end{array}$ \\
\hline Tetracycline $t e t R G$ & 0.05 & 0.09 & $\begin{array}{l}\text { TetR is the repressor of the tetracycline resistance element, TetG is } \\
\text { tetracycline efflux protein }\end{array}$ \\
\hline Trimethoprim $d f r 32$ & 0.05 & 0.03 & $\begin{array}{l}\text { Dihydrofolate reductase and trimethoprim resistance gene, confers } \\
\text { resistance by replacing or substituting antibiotic action target }\end{array}$ \\
\hline
\end{tabular}




\section{Figure legends}

203 Figure 1. Bacterial communities and bacteria-associated antibiotic resistome in groundwater. (a) 204 Heat map illustrates relative abundance of individual bacteria phyla in the negative controls 205 (MilliQ water), upstream controls and wells in Wadi Fatimah across different sampling months. 206 (b) Bacteria alpha diversity in groundwater sampled from Wadi Fatimah across different 207 sampling months, upstream controls and negative controls. Linear line depicts an increasing 208 trend in alpha diversity with time. (c) Venn diagram illustrating the number of unique antibiotic 209 resistance genes detected in Wadi Fatimah (depicted as green) and upstream control samples 210 (depicted as red). Overlapping region shows the number of shared antibiotic resistance genes 211 detected in both Wadi Fatimah and upstream controls.

212 Figure 2. Viral communities in groundwater. (a) Heat map illustrates the relative abundance of 213 individual viral families in the control (MilliQ water), upstream controls and wells in Wadi 214 Fatimah across the different sampling times. (b) Virus alpha diversity in groundwater sampled 215 from Wadi Fatimah across different sampling months, upstream controls and negative controls. 216 Linear line depicts no apparent trend of increment with time. 


\section{References}

Al-Jassim, N., et al., 2015. Removal of bacterial contaminants and antibiotic resistance genes by conventional wastewater treatment processes in Saudi Arabia: Is the treated wastewater safe to reuse for agricultural irrigation? Water Res. 73, 277-90.

Connelly, S., et al., 2018. Distinct consequences of amoxicillin and ertapenem exposure in the porcine gut microbiome. Anaerobe. 53, 82-93.

Grainger, D. J., 1992. A geological excursion in the Wadi Fatima area, near Jiddah, Saudi Arabia. Geology Today. 8, 215-219.

Halliday, E., et al., 2014. Comparison of bacterial communities in sands and water at beaches with bacterial water quality violations. PLoS One. 9, e90815.

Hasan, N. A., et al., 2014. Microbial Community Profiling of Human Saliva Using Shotgun Metagenomic Sequencing. Plos One. 9.

Jumat, M. R., et al., 2017. Membrane Bioreactor-Based Wastewater Treatment Plant in Saudi Arabia: Reduction of Viral Diversity, Load, and Infectious Capacity. Water. 9.

Kaleko, M., et al., 2016. Development of SYN-004, an oral beta-lactamase treatment to protect the gut microbiome from antibiotic-mediated damage and prevent Clostridium difficile infection. Anaerobe. 41, 58-67.

Luo, T., et al., Aqueduct Projected Water Stress Country Rankings. 2015. http://reliefweb.int/sites/reliefweb.int/files/resources/AQUEDUCT\%20PROJECTED\%20WATER\% 20STRESS\%20Country\%20Rankings.pdf. 31 August 2019

Manti, A., et al., 2008. Bacterial cell monitoring in wastewater treatment plants by flow cytometry. Water Environ Res. 80, 346-54.

Ponnusamy, D., et al., 2016. Cross-talk among flesh-eating Aeromonas hydrophila strains in mixed infection leading to necrotizing fasciitis. Proceedings of the National Academy of Sciences. 113, 722-727.

Quince, C., et al., 2017. Shotgun metagenomics, from sampling to analysis. Nature Biotechnology. 35, 833.

Reuter, G., et al., 2017. Saliviruses-the first knowledge about a newly discovered human picornavirus. Rev Med Virol. 27.

Van Goethem, M. W., et al., 2018. A reservoir of 'historical' antibiotic resistance genes in remote pristine Antarctic soils. Microbiome. 6, 40.

Versporten, A., et al., 2018. Antimicrobial consumption and resistance in adult hospital inpatients in 53 countries: results of an internet-based global point prevalence survey. Lancet Glob Health. 6, e619-e629.

Zhang, K., Farahbakhsh, K., 2007. Removal of native coliphages and coliform bacteria from municipal wastewater by various wastewater treatment processes: implications to water reuse. Water Res. 41, 2816-24. 
Click here to download high resolution image

(a) Reative aturaanoe nei

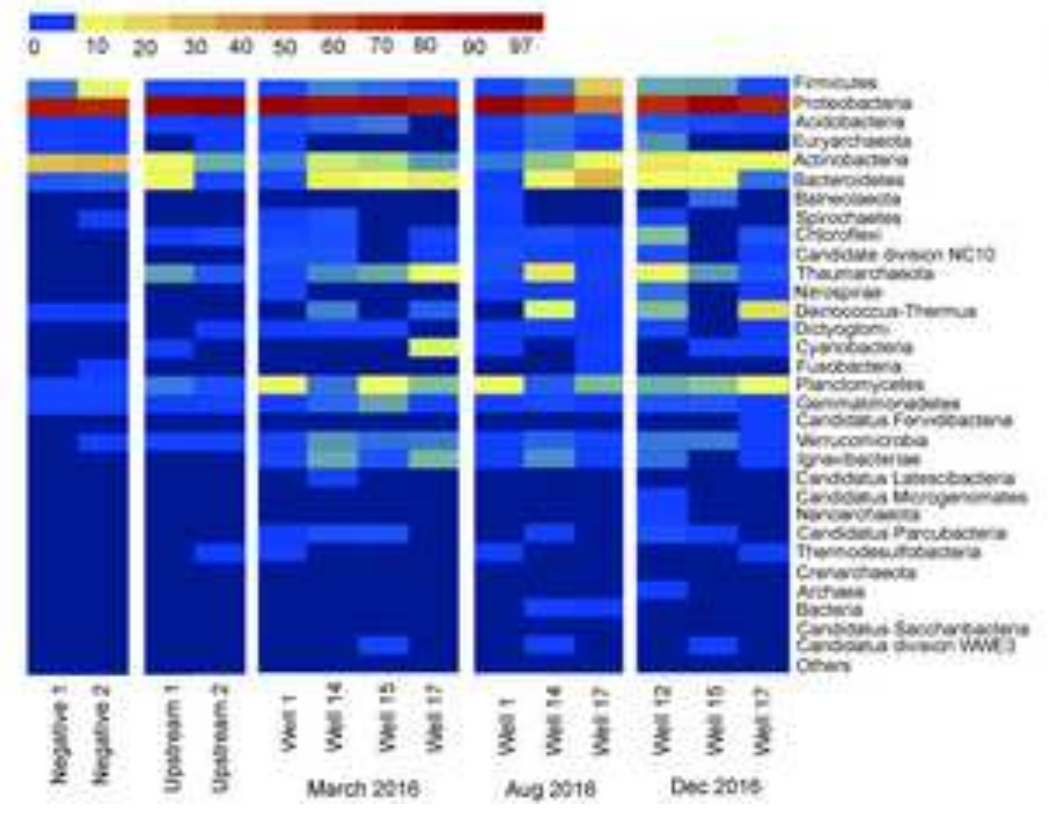

(b)

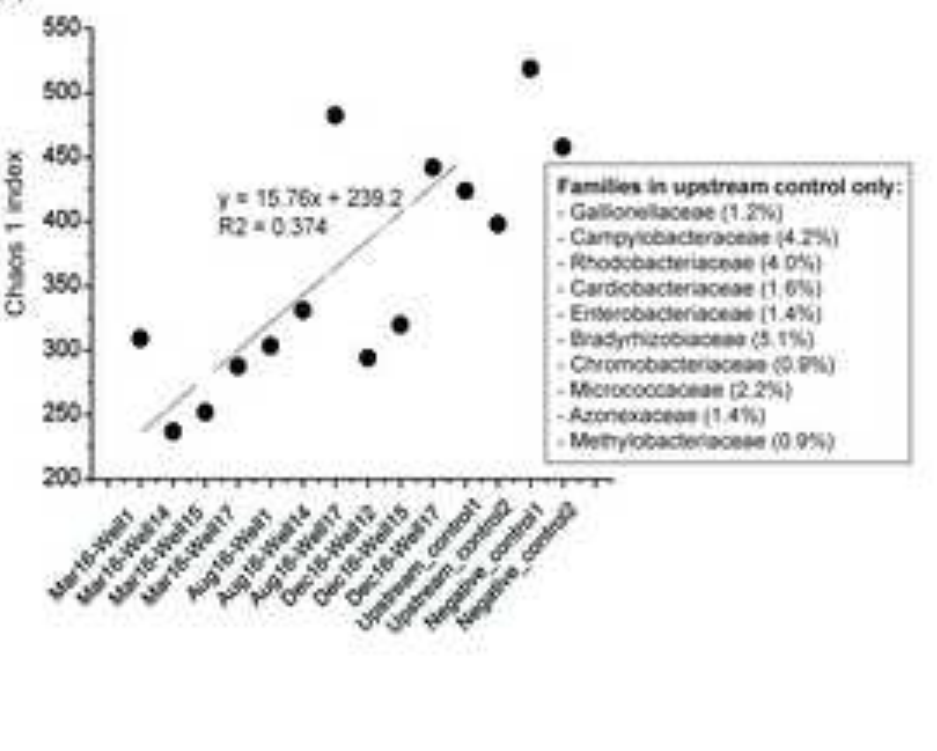

(c)

Antibiotic resistance genes count

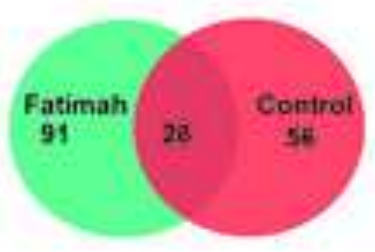


(a) Relative abundance (\%)

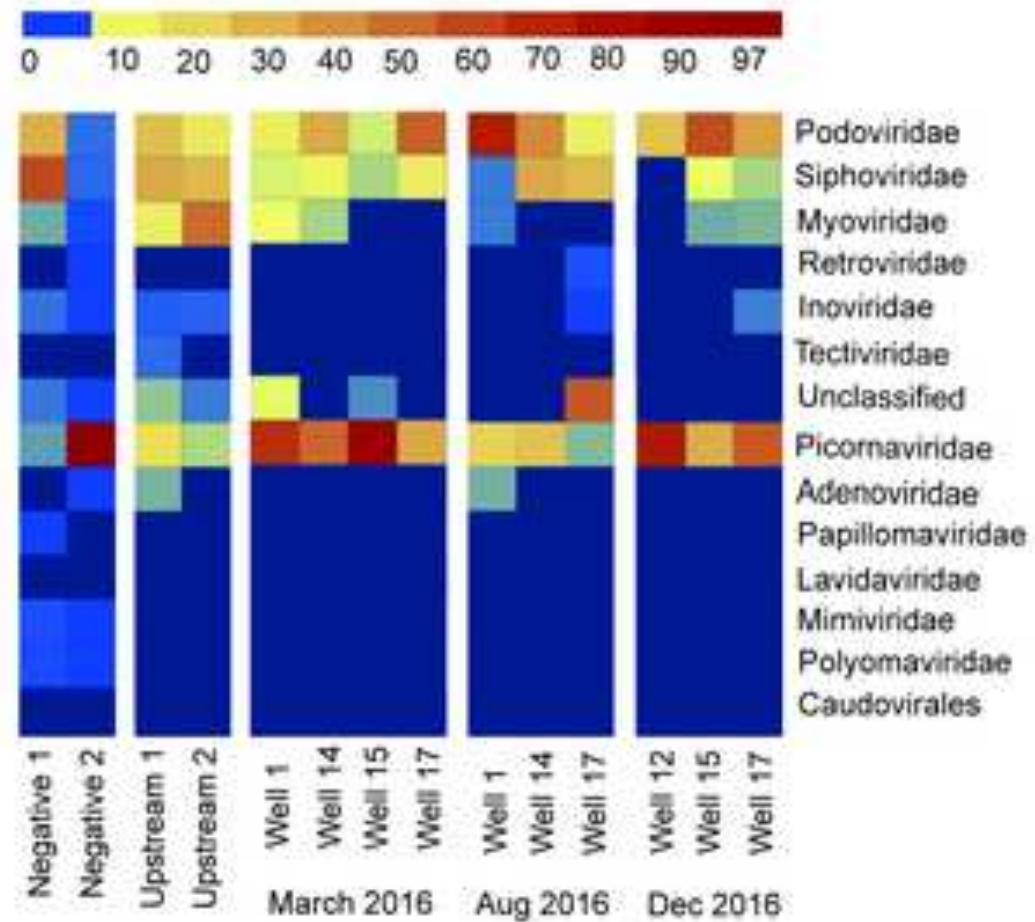

(b)

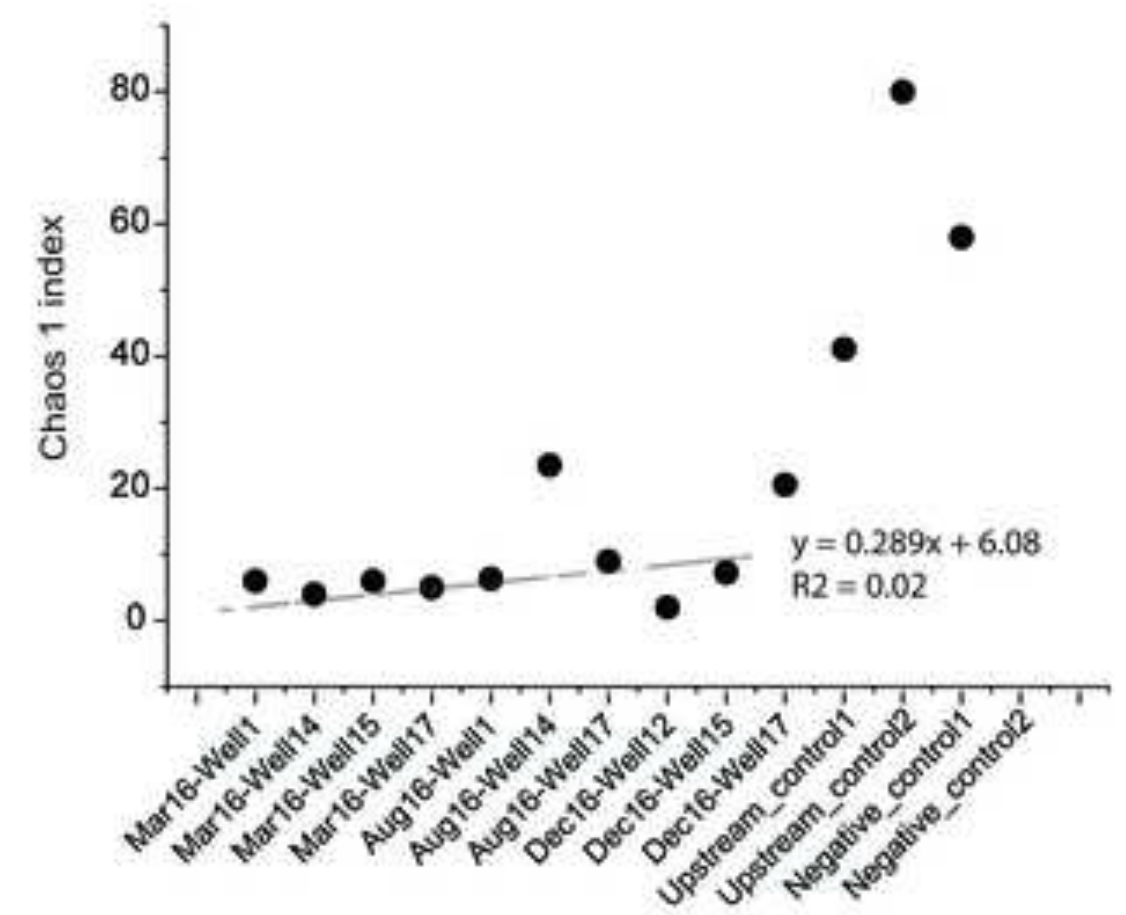


Supplementary Material
Click here to download Supplementary Material: For review - Supplemental Information.docx

Supplementary Material
Click here to download Supplementary Material: For review - Supplemental Information.docx

Clck here to download Supplementary Material: For review - Supplemental In

(1)

(1)

Suplementary . (1) (1) (1) . . . . . . . . . . . . . . . . 


\section{Conflict of interest}

The authors declare no conflict of interest.

\section{conflict of Interest Statement}

